\title{
The Inverse Domination in Semi-total Block Graphs
}

\author{
K. Ameenal Bibi \\ Department of Mathematics \\ Dhanabagiyam Krishnaswamy Mudaliar College \\ for Women (Autonomous), Vellore -1 .
}

\author{
R.Selvakumar \\ Department of Mathematics \\ VIT University, Vellore - 14
}

\begin{abstract}
Let $\mathrm{G}=(\mathrm{V}, \mathrm{E})$ be a simple, finite, undirected graph with $|\mathrm{V}|=\mathrm{n}$ and $|\mathrm{E}|=\mathrm{m}$. Kulli introduced the new graph valued function namely the semi-total block graph of a graph $\mathrm{G}$. Let $\mathrm{B}_{1}=$ $\left\{u_{1}, u_{2}, \ldots, u_{r}, r \geq 2\right\}$ be a block of $G$. Then we say that the point $\mathrm{u}_{1}$ and block $\mathrm{B}_{1}$ are incident with each other, as are $\mathrm{u}_{2}$ and $\mathrm{B}_{1}, \mathrm{u}_{3}$ and $\mathrm{B}_{1}$ and so on. If two distinct blocks $\mathrm{B}_{1}$ and $\mathrm{B}_{2}$ are incident with a common cut point then they are called adjacent blocks. Let $B=\left\{B_{1}, B_{2}, \ldots, B_{p}\right\}$ be the set of blocks of $G$. The semi-total block graph $T_{b}(G)$ of a graph $G$ is the graph whose point set is $\mathrm{V}(\mathrm{G}) \cup \mathrm{B}(\mathrm{G})$ in which any two points are either adjacent or the corresponding members of $G$ are incident. The points and blocks of $G$ are members of $T_{b}(G)$. A non-empty set $D \subseteq V \cup B$ is a dominating set of $T_{b}(G)$ if every point in $(V \cup B)$ $\mathrm{D}$ is adjacent to atleast one point in $\mathrm{D}$ (Muddebihal, M.H. et al 2004). The domination number of $T_{b}(G)$ is denoted by $\gamma\left[T_{b}(G)\right]$ and it is defined as the minimum cardinality taken over all the minimal dominating sets of $T_{b}(G)$. In this paper, we defined Inverse domination in semi-total block graphs. Let $\mathrm{D}$ be the minimum dominating set of $T_{b}(G)$. If $(V \cup B)$-D contains a dominating set $\mathrm{D}^{\prime}$ then $\mathrm{D}^{\prime}$ is called the Inverse dominating set of $\mathrm{T}_{\mathrm{b}}(\mathrm{G})$. The Inverse domination number in semi-total block graph is denoted by $\gamma^{\prime}\left[T_{b}(G)\right]$ and it is defined as the minimum cardinality taken over all the minimal Inverse dominating sets of $T_{b}(G)$. In this paper, many bounds on $\gamma^{\prime}\left[T_{b}(G)\right]$ are attained and its exact values for some standard graphs are found. Its relationships with other parameters are investigated. NordhausGaddum type results are also obtained for this parameter.
\end{abstract}

Keywords: Domination number, Inverse domination number, semi-total block graph and independence number.

\subsection{INTRODUCTION}

Let $\mathrm{G}=(\mathrm{V}, \mathrm{E})$ be a simple, finite, undirected graph with $|\mathrm{V}|=\mathrm{n}$ and $|\mathrm{E}|=\mathrm{m}$. Kulli introduced the new graph valued function namely the semi-total block graph of a graph $G$. Let $B_{1}=\left\{u_{1}, u_{2}, \ldots, u_{r}, r \geq 2\right\}$ be a block of $G$. Then we say that the point $u_{1}$ and block $B_{1}$ are incident with each other, as are $u_{2}$ and $\mathrm{B}_{1}, \mathrm{u}_{3}$ and $\mathrm{B}_{1}$ and so on. If two distinct blocks $\mathrm{B}_{1}$ and $\mathrm{B}_{2}$ are incident with a common cut point then they are called adjacent blocks. Let $B=\left\{B_{1}, B_{2}, \ldots, B_{p}\right\}$ be the set of blocks of $G$. The semi-total block graph $T_{b}(G)$ of a graph $G$ is the graph whose point set is $V(G) \cup B(G)$ in which any two points are either adjacent or the corresponding members of $G$ are incident. The points and blocks of $G$ are members of $T_{b}(G)$. A non-empty set $\mathrm{D} \subseteq \mathrm{V} \cup \mathrm{B}$ is a dominating set of $\mathrm{T}_{\mathrm{b}}(\mathrm{G})$ if every point in $(\mathrm{V} \cup \mathrm{B})$ $\mathrm{D}$ is adjacent to atleast one point in $\mathrm{D}$ (Muddebihal, M.H. et al 2004). The domination number of $T_{b}(G)$ is denoted by $\gamma\left[T_{b}(G)\right]$ and it is defined as the minimum cardinality taken over all the minimal dominating sets of $T_{b}(G)$. In this paper, we defined Inverse domination in semi-total block graphs. Let $\mathrm{D}$ be the minimum dominating set of $T_{b}(G)$. If $(V \cup B)$-D contains a dominating set $\mathrm{D}^{\prime}$ then $\mathrm{D}^{\prime}$ is called the Inverse dominating set of $\mathrm{T}_{\mathrm{b}}(\mathrm{G})$. The Inverse domination number in semi-total block graph is denoted by $\gamma^{\prime}\left[T_{b}(G)\right]$ and it is defined as the minimum cardinality taken over all the minimal Inverse dominating sets of $T_{b}(G)$. In this paper, many bounds on $\gamma^{\prime}\left[T_{b}(G)\right]$ are attained and its exact values for some standard graphs are found. Its relationships with other parameters are investigated. NordhausGaddum type results are also obtained for this parameter.

A non-empty set $\mathrm{D} \subseteq \mathrm{V}$ is a dominating set of $\mathrm{G}$ if every point in V-D is adjacent to atleast one point in $\mathrm{D}$. The domination number $\gamma(\mathrm{G})$ is the minimum cardinality taken over all the minimal dominating sets of $\mathrm{G}$ (Haynes, T.W. et al 1998). A dominating set $\mathrm{D}$ of a graph $\mathrm{G}$ is a split dominating set of $\mathrm{G}$ if the induced subgraph $\langle\mathrm{V}-\mathrm{D}\rangle$ is disconnected (Kulli, V.R. and Janakiram,B. 1997). If V-D contains a dominating set D' then $\mathrm{D}^{\prime}$ is called the Inverse dominating set of G. Then $\mathrm{D}^{\prime}$ is called an Inverse split dominating set of $\mathrm{G}$ if the induced subgraph $\langle\mathrm{V}-\mathrm{D}$ '> is disconnected (Ameenal Bibi, K. and Selvakumar, R. 2008). The Inverse split domination number $\gamma_{s}^{\prime}(G)$ is the minimum cardinality of the minimal Inverse split dominating set of G. The point independence number or the Independence number $\beta_{0}(G)$ is the maximum cardinality among the independent set of points of $\mathrm{G}$. An independent set has pairwise non - adjacent vertices.

\subsection{RESULTS}

We observed the following results for some standard graphs.

Observation 1.2.1:

For any path $P_{n}$ with $n \geq 2$ points,

$$
\gamma^{\prime}\left[\mathrm{T}_{\mathrm{b}}\left(\mathrm{P}_{\mathrm{n}}\right)\right]=\left\lceil\frac{\mathrm{n}}{2}\right\rceil
$$

\section{Observation 1.2.2:}

For any non-separable graph $\mathrm{G}$,

$$
\gamma^{\prime}\left[\mathrm{T}_{\mathrm{b}}(\mathrm{G})\right]=1
$$

Note:

We needed the following theorem for our later results

Theorem 1.2.3:

(K.Ameenal Bibi and R.Selvakumar (2008))

Let $\mathrm{T}$ be a tree such that any two adjacent cut points $\mathrm{u}$ and $\mathrm{v}$ with atleast one of $u$ and $v$ is adjacent to an end point then

$$
\gamma^{\prime}(\mathrm{T})=\gamma_{\mathrm{s}}^{\prime}(\mathrm{T})
$$




\section{Example 1.2.4:}

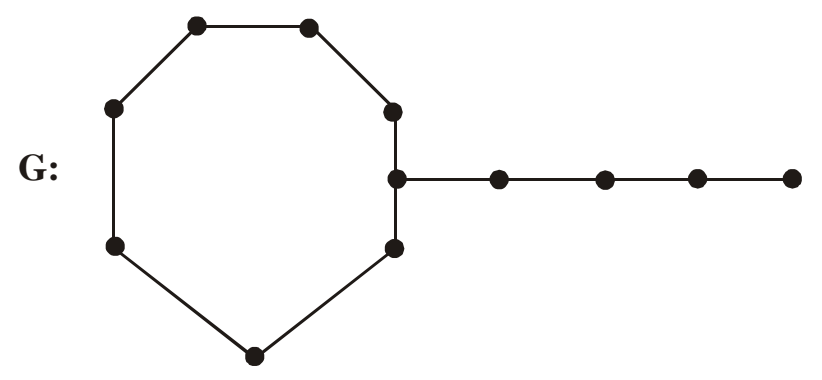

$\mathbf{T}_{\mathrm{b}}(\mathrm{G})$ :

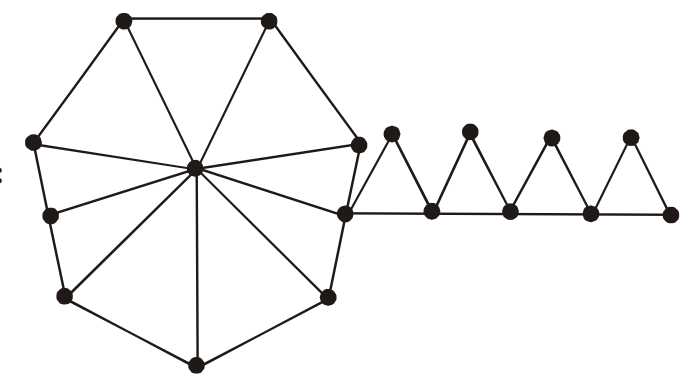

Total number of blocks in G: $p=5$, $\gamma(\mathrm{G})=4, \gamma^{\prime}(\mathrm{G})=4, \gamma\left[\mathrm{T}_{\mathrm{b}}(\mathrm{G})\right]=3$ and $\gamma^{\prime}\left[\mathrm{T}_{\mathrm{b}}(\mathrm{G})\right]=3$.

\section{Theorem 1.2.5:}

For any tree $\mathrm{T}, \gamma^{\prime}\left[\mathrm{T}_{\mathrm{b}}(\mathrm{T})\right] \geq \gamma^{\prime}(\mathrm{T})$.

\section{Proof:}

Let $\mathrm{D}^{\prime}=\mathrm{D}_{1} \cup^{\prime} \mathrm{D}_{2}^{\prime}$ be a minimum inverse dominating set of $T_{b}(T)$ where $D_{1}{ }^{\prime} \subset V(T)$ and $D_{2}{ }^{\prime} \subset\left[V\left(T_{b}(T)-V(T)\right]\right.$. Let $D_{2}{ }^{\prime}=\left\{b_{1}, b_{2}, \ldots, b_{p}\right\}$ where $b_{1}, b_{2}, \ldots, b_{p}$ are points corresponding to the blocks $B_{1}, B_{2}, \ldots, B_{p}$ of $T$. In a tree, each block is $k_{2}$. Let $D_{2} "=\left\{v_{1}, v_{2}, \ldots, v_{p}\right\}$ where $v_{1}, v_{2}, \ldots, v_{p}$ are the points of $T$ which are incident with $\mathrm{B}_{1}, \mathrm{~B}_{2}, \ldots, \mathrm{B}_{\mathrm{p}}$ respectively. Clearly $\mathrm{D}^{\prime} \cup \mathrm{D}_{2}$ " is an inverse dominating set of $\mathrm{T}$.

Thus $\gamma^{\prime}(\mathrm{T})$

$$
\begin{aligned}
& \leq\left|\mathrm{D}_{1}{ }^{\prime} \cup \mathrm{D}_{2}^{\prime \prime}\right| \\
& =\left|\mathrm{D}_{1}^{\prime} \cup \mathrm{D}_{2}^{\prime}\right| \\
& =\left|\mathrm{D}^{\prime}\right| \\
& =\gamma^{\prime}\left[\mathrm{T}_{\mathrm{b}}(\mathrm{T})\right]
\end{aligned}
$$

Hence $\quad \gamma^{\prime}\left[\mathrm{T}_{\mathrm{b}}(\mathrm{T})\right] \geq \gamma^{\prime}(\mathrm{T})$

\section{Theorem 1.2.6:}

For any tree $\mathrm{T}, \gamma^{\prime}\left[\mathrm{T}_{\mathrm{b}}(\mathrm{T})\right] \geq \gamma_{\mathrm{s}}^{\prime}(\mathrm{T})$

\section{Proof:}

From theorem 1.2.3, $\gamma^{\prime}(\mathrm{T})=\gamma_{\mathrm{s}}^{\prime}(\mathrm{T})$.....

From theorem 1.2.5, $\gamma^{\prime}\left[\mathrm{T}_{\mathrm{b}}(\mathrm{T})\right] \geq \gamma^{\prime}(\mathrm{T})$

From (1) and (2) we get the required result.

\subsection{BOUNDS ON $\gamma^{\prime}\left[T_{b}(G)\right]$ \\ Theorem 1.3.1:}

For any graph $\mathrm{G}$ with $\mathrm{p}$ blocks $\gamma^{\prime}\left[\mathrm{T}_{\mathrm{b}}(\mathrm{G})\right] \leq \mathrm{p}$.

\section{Proof:}

Let $B_{1}, B_{2, \ldots, B_{p}}$ be the $p$ blocks of $G$.

Let $\left\{b_{1}, b_{2}, \ldots, b_{p}\right\}$ be the corresponding block points in $T_{b}(G)$ and $\left\{c_{1}, c_{2}, \ldots, c_{t}\right\}$ be the cut points of $G$. If $G$ is non- separable then $\gamma^{\prime}\left[\mathrm{T}_{\mathrm{b}}(\mathrm{G})\right]=1$. If $\mathrm{G}$ is separable with $\mathrm{t}=1$ and $\mathrm{p} \geq 2$ blocks, then consider the following two cases:

\section{Case (i)}

Suppose each block is $\mathrm{k}_{\mathrm{p}}$ then $\gamma\left[\mathrm{T}_{\mathrm{b}}(\mathrm{G})\right]=\mathrm{t}$

Thus $\gamma^{\prime}\left[\mathrm{T}_{\mathrm{b}}(\mathrm{G})\right]<\mathrm{p}$.

\section{Case (ii)}

Suppose each block of $\mathrm{G}$ is either $\mathrm{C}_{\mathrm{p}}(\mathrm{p}>3)$ or a block which is incomplete. Then $D^{\prime}=\left\{b_{1}, b_{2}, \ldots, b_{p}\right\}$ is such that each point of $T_{b}(G)$ not in $D^{\prime}$ is adjacent to atleast one point in $D^{\prime}$. Thus $D^{\prime}$ is the minimum Inverse dominating set of $T_{b}(G)$. Hence $\gamma^{\prime}\left[T_{b}(G)\right]=p$. Combining both the cases, we have $\gamma^{\prime}\left[\mathrm{T}_{\mathrm{b}}(\mathrm{G})\right] \leq \mathrm{p}$.

If $G$ has $t \geq 2$ cut points then the minimum Inverse dominating set may be either $\left\{b_{1}, b_{2}, \ldots, b_{p}\right\}$ or $\left\{c_{1}, c_{2}, \ldots, c_{t}\right\}$. In each case, we have $\gamma^{\prime}\left[T_{b}(G)\right] \leq p$ since $t<p$. Hence the proof.

\section{Theorem 1.3.2:}

If $\gamma^{\prime}(\mathrm{G}) \leq \gamma^{\prime}\left[\mathrm{T}_{\mathrm{b}}(\mathrm{G})\right]$ then $\gamma^{\prime}(\mathrm{G}) \leq \mathrm{p}$ where $\mathrm{p}$ is the number of blocks of $\mathrm{G}$.

\section{Proof:}

Assume $\gamma^{\prime}(\mathrm{G}) \leq \gamma^{\prime}\left[\mathrm{T}_{\mathrm{b}}(\mathrm{G})\right]$.

By theorem 1.3.1, $\gamma^{\prime}\left[\mathrm{T}_{\mathrm{b}}(\mathrm{G})\right] \leq \mathrm{p}$.

Hence $\quad \gamma^{\prime}(\mathrm{G}) \leq \gamma^{\prime}\left[\mathrm{T}_{\mathrm{b}}(\mathrm{G})\right] \leq \mathrm{p}$.

Thus $\gamma^{\prime}(\mathrm{G}) \leq \mathrm{p}$.

\section{Theorem 1.3.3:}

$$
\text { For any connected graph } G, \gamma^{\prime}\left[T_{b}(G)\right] \leq \frac{n}{2}
$$

Proof:

Let $\left\{B_{1}, B_{2}, \ldots, B_{p}\right\}$ be the $p$ number of blocks of $G$ and two adjacent blocks of $\mathrm{G}$ have atleast one point $\mathrm{v}$ in common. Starting from v, consider alternate points of $\mathrm{G}$ and that forms an Inverse dominating set $\mathrm{D}^{\prime}$ of $\mathrm{G}$. If $\mathrm{G}$ contains only one block then start from any point $v$. Let $D^{\prime}=\left\{v_{1}, v_{2}, \ldots, v_{n} / 2\right\}$. Since each point of $\mathrm{G}$ belongs to atleast one block of $\mathrm{G}$, each $B_{i}, 1 \leq i \leq p$ is adjacent to atleast one element of $D^{\prime}$. Hence $\gamma^{\prime}\left[T_{b}(G)\right] \leq\left|D^{\prime}\right| \leq$ $\frac{\mathrm{n}}{2}$.

\section{Theorem 1.3.4:}

For any graph $G, \gamma^{\prime}\left[T_{b}(G)\right] \leq n-\delta(G)$.

\section{Proof:}

Let $\left\{B_{1}, B_{2}, \ldots, B_{p}\right\}$ be the number of blocks of $G$. Let $\mathrm{v}$ be the point of minimum degree $\delta(G)$. Let $v_{1}, v_{2}, \ldots, v_{\delta}$ be the points adjacent to $v$. Without loss of generality, let $v \in B_{1}$. Let $b_{1}, b_{2}, \ldots, b_{p}$ be the block points in $T_{b}(G)$ corresponding to the blocks $\mathrm{B}_{1}, \mathrm{~B}_{2}, \ldots, \mathrm{B}_{\mathrm{p}}$.

$$
\text { Let } \mathrm{D}^{\prime}=\mathrm{V}(\mathrm{G})-\left\{\mathrm{v}_{1}, \mathrm{v}_{2}, \ldots, \mathrm{v}_{\delta}\right\}
$$

We claim tat $\mathrm{D}^{\prime}$ contains atleast one point from each $B_{i}$, if not, let all the points of $B_{j} \notin D^{\prime}$.

Let $\mathrm{V}\left(\mathrm{B}_{\mathrm{j}}\right)=\left\{\mathrm{v}_{1}, \mathrm{v}_{2}, \ldots, \mathrm{v}_{\mathrm{r}}\right\} \subset\left\{\mathrm{v}_{1}, \mathrm{v}_{2}, \ldots, \mathrm{v}_{\delta}\right\}$. Then $\left\{\left(\mathrm{v}_{1}, \mathrm{v}_{2}, \ldots, \mathrm{v}_{\mathrm{r}}\right) \cup \mathrm{v}\right\}$ is a block which contradicts that $\mathrm{B}_{\mathrm{j}}$ is a block. Therefore, D' contains atleast one point from each $B_{i}$, where $1 \leq \mathrm{i} \leq \mathrm{p}$. Obviously, $\mathrm{D}^{\prime}$ is an Inverse dominating set of $\mathrm{T}_{\mathrm{b}}(\mathrm{G})$.

$$
\text { Hence } \gamma^{\prime}\left[\mathrm{T}_{\mathrm{b}}(\mathrm{G})\right] \leq\left|\mathrm{D}^{\prime}\right|=\mathrm{n}-\delta(\mathrm{G})
$$




\section{Theorem 1.3.5:}

For any graph $\mathrm{G}$, number of $\mathrm{G}$.

$\gamma^{\prime}\left[T_{b}(G)\right] \leq \beta_{o}(G)$ where $\beta_{o}(G)$ is the independence

\section{Proof:}

Let $\left\{b_{1}, b_{2}, \ldots, b_{p}\right\}$ be the block points in $T_{b}(G)$ corresponding to the blocks $\mathrm{B}_{1}, \mathrm{~B}_{2}, \ldots, \mathrm{B}_{\mathrm{p}}$ in $\mathrm{G}$. Let $\mathrm{D}^{\prime}=$ $\left\{\mathrm{v}_{1}, \mathrm{v}_{2}, \ldots, \mathrm{v}_{\mathrm{p}}\right\}$ be the maximal independent set of $\mathrm{G}$ which is also an Inverse dominating set of $G$. Then we have the following two cases.

\section{Case (i)}

Suppose $b_{1}$ is a block point in $T_{b}(G)$ which is not adjacent to any point of $D^{\prime}$. Then $V(G)$ - $D^{\prime}$ forms a dominating set of $T_{b}(G)$ and $\left|V(G)-D^{\prime}\right| \leq\left|D^{\prime}\right|$

Therefore $\gamma^{\prime}\left[T_{b}(G)\right] \leq \beta_{o}(G)$.

\section{Case (ii)}

$\mathrm{D}^{\prime}$, then

Suppose each block is adjacent to atleast one point of

$\gamma^{\prime}\left[\mathrm{T}_{\mathrm{b}}(\mathrm{G})\right] \leq\left|\mathrm{D}^{\prime}\right|=\beta_{\mathrm{o}}(\mathrm{G})$.

Hence $\gamma^{\prime}\left[T_{b}(G)\right] \leq \beta_{0}(G)$.

\section{Theorem 1.3.6:}

For any graph $\mathrm{G}$ without end points,

$\gamma^{\prime}\left[\mathrm{T}_{\mathrm{b}}(\mathrm{G})\right] \leq \operatorname{diam}(\mathrm{G})$.

\section{Proof:}

Let $A=\left\{e_{1}, e_{2}, \ldots, e_{k}\right\}$ be the set of lines which constitutes the largest path between any two points of $G$ such that $|\mathrm{A}|=\operatorname{diam}(\mathrm{G})$ and $\mathrm{p}$ be the number of blocks of $\mathrm{G}$.

\section{Case (i)}

If all the elements of A belongs to a single block, then $\gamma^{\prime}\left[\mathrm{T}_{\mathrm{b}}(\mathrm{G})\right]=1 \leq|\mathrm{A}|$.

\section{Case (ii)}

If all the elements of A belongs to different blocks and $\mathrm{G}$ is without end points, then $\mathrm{p} \leq|\mathrm{A}|$. Then by theorem 3.3.1, $\gamma^{\prime}\left[\mathrm{T}_{\mathrm{b}}(\mathrm{G})\right] \leq \mathrm{p} \leq|\mathrm{A}|$.

Hence $\gamma^{\prime}\left[T_{b}(G)\right] \leq \operatorname{diam}(G)$.

\subsection{NORDHAUS - GADDUM TYPE RESULTS}

\section{Theorem 1.4.1:}

For any connected graph $\mathrm{G}$ with $\mathrm{n} \geq 4$ points,

(i) $\quad \gamma^{\prime}\left[\mathrm{T}_{\mathrm{b}}(\mathrm{G})\right]+\gamma^{\prime}\left[\mathrm{T}_{\mathrm{b}}(\overline{\mathrm{G}})\right] \leq 2 \mathrm{n}-1$

(ii) $\quad \gamma^{\prime}\left[\mathrm{T}_{\mathrm{b}}(\mathrm{G})\right] \cdot \gamma^{\prime}\left[\mathrm{T}_{\mathrm{b}}(\overline{\mathrm{G}})\right] \leq \mathrm{n}(\mathrm{n}-1)$

\section{Proof:}

For any connected graph $\mathrm{G}$, from theorem 3.3.3,

$\gamma^{\prime}\left[\mathrm{T}_{\mathrm{b}}(\mathrm{G})\right] \leq \frac{\mathrm{n}}{2}$

Since $G$ is a graph with $n \geq 4$ points and $G$ has no isolates, the number of points of $\overline{\mathrm{G}}$ is less than or equal to $n-1$. Hence $\gamma^{\prime}\left[\mathrm{T}_{\mathrm{b}}(\overline{\mathrm{G}})\right] \leq \mathrm{n}-1$.

Hence the theorem.

\section{Theorem 1.4.2:}

For any connected graph $\mathrm{G}$ with $\mathrm{p} \geq 2$ blocks,

$$
\begin{aligned}
& \gamma^{\prime}\left[\mathrm{T}_{\mathrm{b}}(\mathrm{G})\right]+\gamma^{\prime}\left[\mathrm{T}_{\mathrm{b}}(\overline{\mathrm{G}})\right] \leq 2 \mathrm{p} . \\
& \gamma^{\prime}\left[\mathrm{T}_{\mathrm{b}}(\mathrm{G})\right] \cdot \gamma^{\prime}\left[\mathrm{T}_{\mathrm{b}}(\overline{\mathrm{G}})\right] \leq \mathrm{p}^{2} .
\end{aligned}
$$

Proof:

From theorem 1.3.1, $\gamma^{\prime}\left[T_{b}(G)\right] \leq p$. Since $G$ is a connected graph with $\mathrm{p} \geq 2$ blocks, the number of blocks of $\overline{\mathrm{G}}$ is less than or equal to $\mathrm{p}$.

$$
\begin{aligned}
& \text { Hence } \gamma^{\prime}\left[\mathrm{T}_{\mathrm{b}}(\overline{\mathrm{G}})\right] \leq \gamma^{\prime}\left[\mathrm{T}_{\mathrm{b}}(\mathrm{G})\right] \leq \mathrm{p} . \\
& \text { Hence the theorem. }
\end{aligned}
$$

\subsection{CONCLUSION}

Graphs can be used to study the structure of World Wide Web. We can determine whether two computers are connected by a communication link using graph models of computer network. We can also use graphs to schedule examinations and assign channels to television stations. Graphs are used as models to represent the competition of different species in an ecological niche, in computing the number of different combinations of flights between two cities in an airline network, in finding the number of colours needed to colour the regions of a map.

In this paper, many bounds on $\gamma^{\prime}\left[\mathrm{T}_{\mathrm{b}}(\mathrm{G})\right]$ are attained and its exact values for some standard graphs are found. Its relationships with other parameters are investigated. NordhausGaddum type results are also obtained for this parameter.

\subsection{REFERENCES}

[1] Ameenal Bibi, K. and Selvakumar, R (2008). Inverse domination in semi-total block graphs. Proc. of the International Conference on Graph Theory and its Applications, Dept. of Mathematics, Amrita Vishwa Vidya Peetham, Ettimadai, Coimbatore. December 11-13.

[2] Cockayne, E.J. and Hedetniemi S.T. (1977). Towards a theory of domination in graphs. Networks, 7. pp. 241-267.

[3] Domke G.S., Dunbar J.E. and Markus L.R (2007). The Inverse domination number of a graph, Feb' (2007).

[4] Harary, F. (1969). Graph Theory, Addison-Wesley, Reading Mass.

[5] Kulli, V.R. and Sigarkanti S.C. (1991). Inverse domination in graphs. National Academy Science Letters, 15.

[6] Kulli, V.R. (1976). The semi-total block graph and total block graph of a graph. Indian Journal of Pure and Applied Maths, 7: 625-630.

[7] Muddebihal, M.H., Usha P. and Sigarkanthi S.C. (2004). Domination in semi-total block graphs. Bulletin of Pure and Applied Sciences. Vol. 23E (No. 1) pp. 195-202.

[8] Nordhaus, E.A. and Gaddum J.W. (1956). On complementary graphs. Amer.Math.Monthly, 63. pp. $175-177$.

[9] Ore, O. (1962). Theory of Graphs. American Mathematical Society Colloq. Publ., Providence, RI, 38 . 